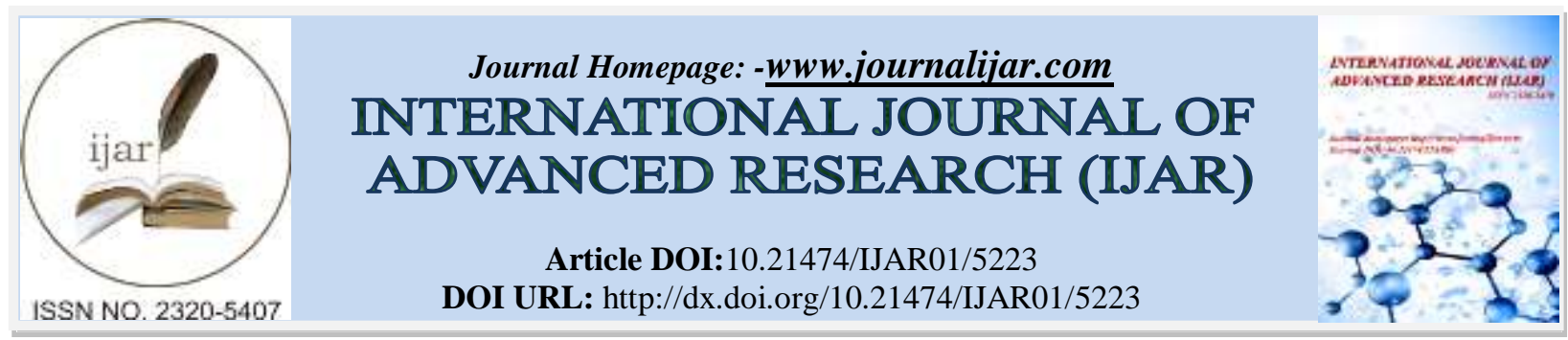

RESEARCH ARTICLE

\title{
STIGMA AND DISCRIMINATION OF HIV POSITIVE PREGNANT WOMEN AND MOTHERS IN THE HOME, COMMUNITY AND HEALTH CARE SETTINGS.
}

Juvina Caren Hannah and Rajan Patil.

\section{Manuscript Info}

[..........................

Manuscript History

Received: 20 June 2017

Final Accepted: 22 July 2017

Published: August 2017

\section{Abstract}

Background: Adult HIV prevalence in India is estimated at $0.30 \%$ among males and $0.22 \%$ among females. More than $90 \%$ of women acquire HIV from their husbands or their sexual partners, not due to their own sexual behavior. The NACO Technical Estimate Report (2015) estimated that 35 thousand HIV positive pregnant women in India needed Prevention of Parent to child transmission (PPTCT) services. Experience worldwide confirms that women tend to suffer more than men from HIV related stigma in terms of loss of respect, employment, protection and property rights that places women at a greater disadvantage in communities, largely so in developing nations.(1)

Objective: The first objective of the study is to identify the day to day challenges that the women living with HIV face in terms of physical dimension ,psychological dimension, socio-economic dimension, health care dimension and how the stigma associated with the disease makes it all the more complex for them in their livelihood. The second objective is to study the stigma and discrimination faced by HIV positive pregnant women and mothers in the home, community and health care settings.

Method: Key informant interviews were conducted with 11 HIV positive women who were either pregnant or mothers. The interviews were conducted in two public health care settings. Semi- structured questionnaire was used. The interviews were audio recorded and extensive notes were also taken. These were translated from Tamil language, transcribed and openly coded. It was next organized into domains, themes and sub-themes.

Results: Stigma and discrimination, at the home, community and health care settings, do exist against the HIV positive women. Poverty and other challenges combined with stigma make it worse and increase the suffering of the women with HIV all the more. Stigma is a disease in itself.

Conclusion:It is a known fact that HIV/AIDS has no cure. But stigma and discrimination against the women infected with HIV is preventable, creating a supportive environment for them for the rest of their life. Combined efforts to reduce the stigma and discrimination need to be taken along with measures to eradicate HIV/ AIDS in order to yield the best outcome. 


\section{Introduction:-}

Indian women are affected by discrimination in many spheres of their lives. Be it in the family, community, village , town, city, school, college and at a variety of work places- discrimination, violence and marginalization are visible. When women are also affected by diseases such as HIV /AIDS, their challenges multiply by several fold.(2)When they become pregnant, their challenges further multiply. The social stigma associated with HIV/AIDS and in particular with socially oppressed women, combine to push women's coping skills to a breaking point. Many examples of discrimination against HIV positive women, and the violations of their basic rights, as well as entitlements for care, support and treatment in the home, community and public health care settings are seen. On October 28 2007, a woman who had gone to the Kalyani Jawaharlal Nehru Memorial Hospital in Nadia in West Bengal for pregnancy related problems was moved to an isolated bed and a sticker marking her as HIV positive was stuck to her forehead. (3)

Rationale: In a patriarchal society, a woman is vulnerable. When she gets pregnant, she becomes even more physically and emotionally at stake. Adding to it, her vulnerability increases when she is HIV positive. The intersectionality of these three issues complicate the vulnerability of these women.(4) On a personal front, the researcher had witnessed the plight of many HIV positive women for the past two years which triggered an interest in her to study these women further. This is the reason why she felt the initiative to do this study.

Objective of the study: 1 . To study the day to day challenges faced by the HIV positive women in terms of physical suffering, psychological, socio-economic, spiritual, and health care related dimensions.2. To study the stigma and discrimination faced by HIV positive pregnant women and HIV positive mothers in the home, community and health care settings.

\section{Methodology:-}

Study design: The study was exploratory in nature. Each respondent was interviewed in depth which lasted around 20-25 minutes to explore their feelings, emotions, perceptions, the difficulties they faced, attitude towards life, how and from whom they acquired the infection, their economic status, the challenges they faced at the integrated counseling and testing centers, and the criticism they had to face from the family, society and health care members.

Study area: The study area was the counseling center at Raja Sir Ramaswamy Mudaliar (RSRM) Government hospital and Kilpauk Medical Hospital, Chennai. RSRM hospital comprises mainly of women folk from the neighbouring rural districts of Chennai and women migrant labourers who seek employment in Chennai. RSRM and Kilpauk Medical Hospital cater to the needs of HIV positive pregnant women. There is a separate voluntary testing center for HIV women at both the hospitals and an anti retro viral pharmacy. The antenatal ward constitutes of both HIV infected pregnant women and non infected women. The bed strength of this ward is 20.

Study participants: The respondents in both these hospitals were approached with the help of Mithras Foundation, directed by Dr.Amudha Hari, which is a non Governmental organization in Chennai, which was formed with a vision to enlighten and empower the marginalized community. The participants were selected purposively with the help of three health workers. The health workers helped the researcher to interview the study participants who comprised of 4 pregnant women infected with HIV and 7 mothers living with HIV.

Study tool: The tool was a semi-structured interview guide which was developed based on previous studies done on stigma and discrimination faced by pregnant women with HIV and mothers living with HIV. Open ended questions were framed with the help of the researcher's guide and were categorized under the headings namely home, community and health care settings. Demographic details were also collected prior to starting the interview. Ethically, the study was approved by the IRB of the School of Public Health, SRM University.

Data Collection Procedure: Key informant interviews were conducted with the 11 study participants and the interviews were recorded after obtaining a written informed consent. Each study participant was assured that the anonymity and confidentiality of information they share would be maintained. An opportunity was provided at the end of each interview session for clarifications and each of the participant was appreciated with a cash amount of 100 rupees. 
Coding and Analysis: The transcripts were typed out by listening to the audio recordings. They were then openly coded and then the similar codes were brought together collectively and a theme was framed for each of these similar types of codes.

Table showing Domains, Themes and subthemes

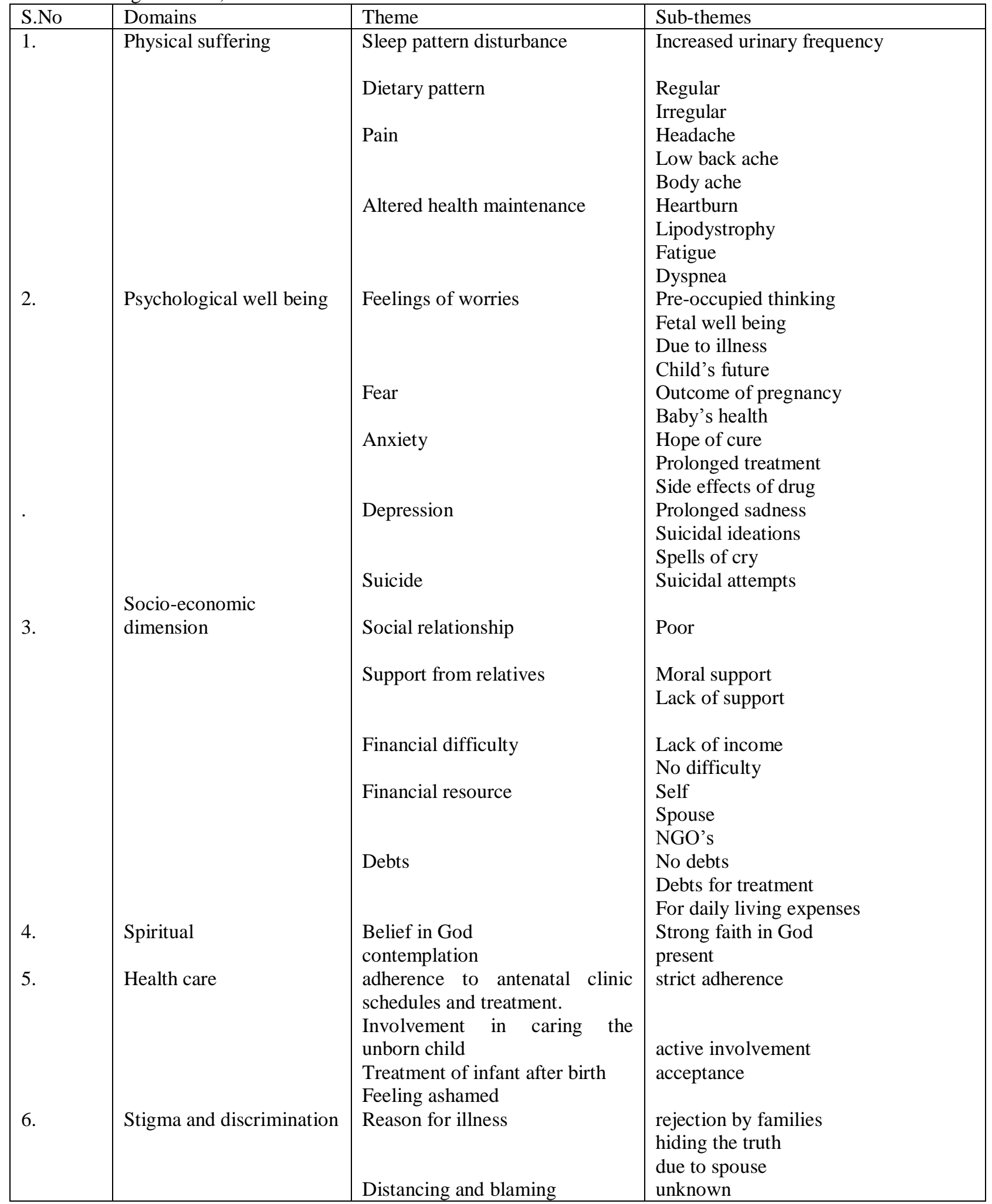




\begin{tabular}{|l|l|l|}
\hline & & $\begin{array}{l}\text { earlier blood transfusions } \\
\text { internalized shame } \\
\text { personalized stigma } \\
\text { negative self image } \\
\text { fear of discrimination } \\
\text { fear of disclosure } \\
\text { fear of social acceptance } \\
\text { loss of family support } \\
\text { lack of social support } \\
\text { social rejection } \\
\text { feeling of insecurity } \\
\text { alienation }\end{array}$ \\
\hline
\end{tabular}

\section{Results and Discussion:-}

The first objective of the study is to capture the challenges faced by these women in their day to day life which can be labelled as physical, psychological, societal, financial constraints, spiritual dimension and their adherence to treatment and follow up. As we know, health is a sum of all these components namely the physical, mental, and social well being and not merely the absence of disease or infirmity. Therefore, in order for these pregnant women and mothers living with HIV to be healthy, they should have a balance between all the dimensions of their life. Firstly, the researcher focuses upon the physical well being of these women. Any healthy pregnant woman would have some form of minor ailments during the time of her pregnancy. Needless to say, these are HIV positive pregnant women who are treated with anti retro viral therapy. Their physical suffering is double fold. "I am getting severe leg pain and back pain when I have to wait for the bus for hours together", reported a HIV positive pregnant woman aged 22. The four pregnant women who were interviewed reported that they did have increased urinary frequency and this led to sleep pattern disturbance during the night time which in turn led to day time sleeping. The dietary pattern was regular for three of these women whereas for one woman, it was irregular because she was in the first trimester of her pregnancy. She reported of frequent bouts of nausea and vomiting. Her facial expression showed that she was dull and fatigued. Lipodystrophy was noticed in two pregnant women. Heartburn and dyspnea were very mild and occasionally reported by the women. "I ensure that i take a solid meal before taking my ART medication, otherwise it will result in heartburn". The women were very cautious about the intake of nutritious food though it was not affordable by all of them. But the pregnant women ensured that they took extra care of their dietary practices for the sake of the unborn child.

Moving on to the psychological well being, feelings of fear, worry and anxiety were very common among these women. Fear that the baby would also be infected with HIV was commonly seen. However, one woman said that, " I am taking my ART medicine regularly and the doctor told that there are very less chances for the baby to get infected. So I do not have fear about transmission of infection". The same lady reported that, "when I first came to know that I was HIV positive, I felt like dying. But now I am little bold and strong. Somehow, I have to give birth to this baby nicely, without the baby developing any complications. All my family members are very anxious about it". It was seen that pre-occupied thoughts and feeling worried were common among these women ,but at the same time, they had a desire to give birth to HIV free babies. One of the mother who was interviewed, her son was also HIV positive. He was five years old and the mother was insisting that such a plight should not occur in other children's lives. She said that there should not be any more innocent victims of the disease. It is a heart wrenching experience to see children go through the HIV infection, which is absolutely not their fault. With the advent of many ART centers and the knowledge about the spread of the disease, through information, education and communication, HIV spread and the incidence of cases has decreased significantly.

Women living with HIV have suicidal ideations on their mind. "many a times I have attempted suicide. Do not know how to face life as it becomes a big question mark", expressed one woman with sadness and tears crawling over her face. Many women reported of spells of cry and depression for prolonged periods of time. They were left with an uncertain future. Fear of death and more often of life itself and how they are going to take care of their children, their future, livelihood, facing criticism and judgemental attitude from their families and society, all these things had a huge toll on the lives of these women. Support from relatives was very minimal and most of these women did not disclose their HIV positive status to their relatives and friends, sparing the immediate family members who obviously come to know about the infection that the women carry. If the women had disclosed their status to friends 
and family, the support and affection which they now experience would also be wiped off. That was the view point of these women.

Financial constraints were pre-dominant among the women. They faced huge economic burden and financial difficulty. Most of these women, except for two, were from a very poor socio-economic background. One of the woman interviewed, literally did not have a roof over her head. She lived in the pavements and the side walks of the road. She had two girl children and her husband worked as a daily wage labourer. She was orphaned when she was four years old and then moved into her aunt's house. There she used to live with her aunt and her brothers. When the aunt came to know of her positive status, she was forced to leave the house and all her belongings were thrown outside the house. Ever since she has been living on the platform with no house to live in. During the narrative, she was frequently talking about her poverty and how she is unable to provide food for her children. According to her, HIV was not a real problem but her poverty seemed to be an unmoved mountain standing before her. Her face and the way she expressed herself told that she had been through a lot. Some of them were in debt and did not know to find their way out to earn an income and make a living. One lady reported that her husband lost his job when the employer came to know that he was HIV positive.

"My husband casually told his colleague that he is HIV positive and this news reached the boss' ears and he was shunned from his job". The stigma and discrimination associated with HIV can have devastating consequences on the lives of the infected person along with his kith and kin. One lady reported that earlier she used to work as a tailor in a garment factory. She made a decent amount of money then. But now after she was infected with HIV, she was not able to continue her work further because of the leg pain, weakness and disability which comes along with the infection. Therefore, she was not able to contribute her share to cover the family's expenses which resulted in poverty. Most of the women had learnt to live with HIV but they were unable to face the critical situation of poverty playing a havoc in their lives. HIV was considered insignificant according to them when compared to the financial burden that they were facing. One mother with HIV was almost in tears when she spoke about her paralysed, HIV positive husband at home. She was working as a house maid and barely had the money to feed her two young daughters. "Only I know how much I struggle to buy half litre of milk, a day. My husband lies like a vegetable at home and he is not even able to take care of himself. Along with this disease, I myself feel very weak but somehow I have to manage and go to work everyday to make both ends meet. I cannot stand to see my children be on empty stomach throughout the day". Poverty has become the deadliest of all diseases which has to be addressed immediately, giving top priority.

Most of them had a strong belief in God. "Now I have left everything in the hands of God. Only He has to show me and my children a good path. Whatever has happened to me, its okay, but my children should not suffer because of me. They should have a good and secure future". One women blamed God for He gave her HIV. She mentioned that all through her life, she has maintained a sinless and respectable life and she called it her fate and blamed that if God ever existed, why should He give her such a deadly disease. It can be seen that the disease led the woman to question her faith in God. It was very noticeable that the women had a huge deal of concern for their children more than themselves. At all costs, they wanted to see happiness in their children's faces. This was their predominant concern.

When it came to the role and responsibility of a woman and a mother, they did care a lot about the unborn child. Any mother or woman would have the natural instinct in her to care, provide and protect her children. The HIV positive women had it all the more. Because, their lives were infested with the depriving disease, they were very cautious to protect their unborn with all that they have. They went for regular check up to the health center, irrespective of any shame and disgrace that they faced. "Even if I have to wait in long queue to see the doctor, I don't mind, because my baby has to be healthy.Some doctors examine us at the end because we are HIV positive, but we do not mind it. They say they have to change the gloves and wear double gloves for examining us. So they make us wait. But we do not mind it for the sake of welfare of our baby." The women were very careful to take their medicine on time and strict adherence to the treatment regimen was noticed. The health worker and the counsellor in the Integrated testing and counseling centre prompt them to collect the ART drugs on time. The women are aware that if they take the ART drugs on time, the longevity of life can be prolonged. After the birth of their babies, they are aware and bring their babies and children to the vaccination centre as per the prescribed schedule and pay due attention to all the details. "My baby was immediately tested if she was HIV positive after birth and she was administered the drops. Then after three months, again they tested her." The mothers are very cautious when it 
comes to the health of their children. None of them were careless about the health and well being of their children. A deep sense of motherly love could be felt by the researcher as she talked with them.

Most of the women had contracted the disease from their husbands. One of them got the infection from her father and she was in love with her uncle's son. He, despite knowing the fact that she was HIV positive, married her since he did not want to break the promise of love to her. Some men were very loving and took good care of their wives. One of them said that she got it from previous blood transfusion, but she was not very sure about it. Despite knowing the fact that they are infected, some men get married and purposely transmit the infection to their wives. The entire life of the woman becomes a question once she gets infected. A woman's life in general is faced with so many challenges. Once she gets infected with HIV, everything before her becomes a standstill. It takes great courage and support from peers, family and friends for her to move ahead in life. This is often not present because of the stigma and discrimination associated with this disease. We shall see this in detail in the following chapter of discussion.

Stigma and discrimination at the home, community and health care setting:

\section{At home:}

Stigma, discrimination and its parameters include guilt, negative self image, internalized shame, (felt by the respondents) social rejection, isolation and alienation which leads to distancing oneself from the community , withdrawn attitude and distancing from social gatherings and finally is blamed by others for being a carrier of the disease. This could be prevented if the family, community and health care providers offer their support, love and care which is not often the case. Stigma, though has been reduced a lot, still prevails which was evident from the narratives of the HIV positive women. At the home frontier, the mother-in-law was the main person who showed discrimination against the HIV positive woman. A woman is the enemy of another woman. This saying proves true. Though in many instances, the husband( son of the mother-in-law) is the culprit, who transmits the infection to his wife, the woman is being blamed and discriminated. A mother of two children was forced to move out of the house by the in laws, once they came to know that she was HIV positive. She said, " my mother-in-law used to verbally abuse me all the time. I have to look into the affairs of the entire household and cook food for everyone late at night. Sometimes, I cannot take my medicine on time, because by the time i take food, it will be very late. My mother-inlaw insists me to prepare food late at night only. She does not have any concern for me that I have to take the tablet. I endure too much torture. They even pulled my son away from me." In most of the cases, the husbands were supportive. There was one woman who shared her sentiments that her husband would not disclose the wife's HIV status even to his own family members with fear that they would discriminate her if they came to know. Once the family members, come to know that the woman is infected, the discrimination starts. Till then, they are supportive. Some mothers-in-law, even went to the extent of searching for another bride for their sons, though they know that the son is the source of infection. The discrimination starts with the home and extends to the community. In another family, the HIV positive woman was not allowed to cook because of the fear that she may pollute the dishes. With the judgemental attitudes by the family and continuous blaming and discrimination against the women, they build up feelings of guilt, shame, scorn and ridicule within them, which leads to inferiority complex and they tend to isolate themselves from the family and society for fear of being hurt further.

\section{At the community:}

At the community level, discrimination was lesser when compared to the home, because the respondents did not disclose their HIV status to their friends or other neighbours for fear of being stigmatized and discriminated. The immediate family members are the ones who come to know of the HIV infection at first. When the women, experience so much of discrimination at the home, at which she seeks more support and love, she gets frightened to disclose her status to friends and neighbours who are the close community within which she encompasses herself.

"I am scared that the community will discriminate me, therefore I do not reveal my status to anyone". One woman experienced severe difficulty when she had to cremate the body of her husband who had died due to AIDS. Her family members came to know that he was HIV positive and they did not even come to support the woman when she had to receive the dead body from the Government Tuberculosis hospital. She was literally left all alone with no relatives, family or friends to support and console her over the death of the husband. Such is the plight. For any human being, love, care, affection and support from near and dear ones is very crucial for a healthy, sustained and enriched life. When physical sickness creeps into our lives, we need all the more love and support from our beloved ones. That is the natural tendency and expectation of any human being. The same is true for the HIV positive 
women. But sadly, due to myths, misconceptions and false ideologies, they have been refused love, ignored, neglected, left uncared for and denied, marginalised, discriminated in their own homes and the society.

Some of them had the openness in revealing their HIV positive status. One HIV positive mother shared that all the people living near her, her neighbours, know her status. She seemed very confident to deal with any situation that came across her way. She said that if they are ready to accept her, it's okay and even otherwise she did not have any grievances. The society ought to give a chance for the HIV positive women to come out boldly and reveal their status without the fear of being discriminated.

\section{At the health care setting:}

In the health care settings, stigmatization and discrimination were significant. One woman shared that the nurses would gossip about her and the baby when she was in the post-natal ward after a C-section. She felt that it would be better if the nurses and doctors had more awareness and treat them with care and compassion just like everyone else. Even when the para- medics knew that the baby born to HIV positive mother was HIV negative, they would use double gloves to immunise the baby. The HIV positive mother felt humiliated by this action because it not only involved her, but for no reason was involving her child also. The mothers had a great sense of love and affection towards their children and such kind of demeaning behaviour by the health care staff, hurt them. During the earlier days, the doctors refused to examine the HIV positive patients with their stethoscope because they felt the apparatus would get contaminated if it touched a HIV positive patient. Some HIV positive patients were very much offended by this kind of treatment by the doctors, and they stopped visiting the hospital to get their ART medications. Even now, I heard from a mother that the doctors make them stand at a distance and do not even use their stethoscope to examine their children Then after health education and supportive motivation from the health workers, they would oblige to visit the hospital. It showed that this kind of discrimination had a dangerous effect in increasing the virulence of the virus and leaving many new HIV positive cases unidentified. This could have detrimental effects in decreasing the incidence of the infection. Some respondents revealed that if they are discriminated in the Government hospitals, they would visit the private hospitals and dental clinics for immediate treatment without revealing that they are HIV positive. This could cause contamination of the instruments in the clinic with the HIV positive person's blood and infect many other innocent lives. This could be prevented if stigma and discrimination against HIV positive women did not prevail.

\section{Limitations:}

The study was limited to a period of four weeks. More pertinent details could be collected if the study covered increased number of participants from different walks of life and from other parts of the state of Tamilnadu.

\section{Suggestions:}

The researcher would suggest a study which involved in-depth interviews with women sex workers, injectable drug users, truck drivers and pregnant women and mothers who did not belong to or were supported by a NGO. The reason would be to study the stigma and discrimination faced by different sections of the society in their perception. Would be ideal if the family members, friends and health care providers were also involved in the interview to study the discrimination from different view points.

\section{Conclusion:-}

Stigma and discrimination has become a disease in itself. Rather it is worse than HIV/AIDS. Public health interventions targeted to reduce the incidence of new cases should be focused upon the reduction of stigma associated with the disease. Lives of these women living with HIV can be more pleasant and productive if they are able to meet the challenges that they face in everyday life with courage and sans stigma. Even the highly educated need to learn more with their hearts than their minds for contributing towards the welfare of these women. A little amount of patience, understanding and kindness can go a long way. Apparently, that is what the women living with HIV need. (5)

\section{Reference:-}

1. Colombini M, Mutemwa R, Kivunaga J, Stackpool Moore L, Mayhew SH. Experiences of stigma among women living with HIV attending sexual and reproductive health services in Kenya: a qualitative study. BMC Health Serv Res [Internet]. 2014 Sep 20 [cited 2017 Jun 6];14. Available from: http://www.ncbi.nlm.nih.gov/pmc/articles/PMC4261560/ 
2. Godbole KG, Kulkarni SS, Godbole GP, Kulkarni AM. Experiences from Garbha-Swasthya helpline. Indian J Public Health. 2015 Apr 1;59(2):149.

3. Rahangdale L, Banandur P, Sreenivas A, Turan J, Washington R, Cohen CR. Stigma as experienced by women accessing prevention of parent to child transmission of HIV services in Karnataka, India. AIDS Care. 2010 Jul;22(7):836-42.

4. Dahlui M, Azahar N, Bulgiba A, Zaki R, Oche OM, Adekunjo FO, et al. HIV/AIDS Related Stigma and Discrimination against PLWHA in Nigerian Population. PLoS ONE [Internet]. 2015 Dec 10 [cited 2017 Jun 6];10(12). Available from: http://www.ncbi.nlm.nih.gov/pmc/articles/PMC4675522/

5. Paudel V, Baral KP. Women living with HIV/AIDS (WLHA), battling stigma, discrimination and denial and the role of support groups as a coping strategy: a review of literature. Reprod Health. 2015;12:53. 